\title{
Protección internacional de los derechos humanos: los mecanismos extra-convencionales de las Naciones Unidas
}

Miguel de la Lama Eggerstedt *

\section{Introducción}

Uno de los instrumentos de más fácil acceso y más efectivos con que cuenta la Organización de las Naciones Unidas para proteger los derechos humanos en cualquier parte del mundo son los llamados mecanismos extra-convencionales, es decir, aquellos que derivan de mandatos concretos establecidos por resoluciones de la Asamblea General o de la Comisión de Derechos Humanos y del Consejo Económico y Social. Se trata de mecanismos abiertos a ciudadanos de todos los Estados y a organizaciones no gubernamentales de todas partes del mundo, sumamente flexibles en cuanto a las reglas de admisibilidad de las comunicaciones recibidas y de tramitación bastante rápida. Los mecanismos convencionales, es decir aquellos establecidos específicamente por tratados, son en cambio de más difícil acceso y de tramitación más lenta. Considérese entre estos últimos el Protocolo Facultativo del Pacto Internacional de Derechos Civiles y Políticos, la Convención contra la Tortura y otros Tratos o Penas Crueles, Inhumanos o Degradantes y el artículo $14^{\circ}$ de la Convención Internacional sobre la Eliminación de todas las Formas de Discriminación Racial.

Los mecanismos extra-convencionales tienen su origen en la resolución 1235 (XIII) del Consejo Económico y Social (ECOSOC) de

\footnotetext{
* El autor es Profesor Asociado de la Facultad de Derecho de la Pontificia Universidad Católica del Perú y Secretario del Grupo de Trabajo sobre las Desapariciones Forzadas o Involuntarias de las Naciones Unidas. Sus opiniones son expresadas a título estrictamente personal y no comprometen a la Organización ni al Grupo de Trabajo.
} 
6 de junio de 1967. Mediante dicha resolución el ECOSOC autorizó a la Comisión de Derechos Humanos y a su Subcomisión a debatir en público sobre violaciones notorias de los derechos humanos y de las libertades fundamentales en los países en que persistían políticas oficiales de dominación colonial, discriminación racial, de segregación o de apartheid. A partir de entonces, se inicia una evolución que permite a la Comisión de Derechos Humanos examinar públicamente, año tras año, la violación de los derechos humanos y de las libertades fundamentales en cualquier parte del mundo, y en particular en los países y territorios coloniales y dependientes.

El primero de los mecanismos extra-convencionales establecido por la Comisión de Derechos Humanos tuvo un ámbito geográfico. Se trata del Grupo Especial de Expertos de la Comisión sobre el África Meridional, constituido en 1967. La Asamblea General estableció por su parte el Comité Especial encargado de investigar las prácticas israelíes que afectan los derechos humanos de la población de los territorios ocupados. Posteriormente, la Comisión de Derechos Humanos estableció en 1975 el Grupo de Trabajo ad hoc encargado de examinar la situación de los derechos humanos en Chile, reemplazado en 1979 por un Relator Especial y terminado en 1990.

Siguieron luego diversos mandatos sobre países determinados, entre los que cabe mencionar la Relatoría Especial sobre la situación de los derechos humanos en Guatemala, encargada luego a un Representante Especial y posteriormente a un Experto Independiente y hoy también terminada; las relatorías especiales sobre la situación de los derechos humanos en el Afganistán; en Guinea Ecuatorial, hoy encargada a un Representante Especial; en el Iraq; en el territorio de la Antigua Yugoslavia; en Myanmar; en el Sudán; en la República Democrática del Congo (ex Zaire); en Burundi; en los territorios palestinos ocupados desde 1967; y en Cuba, en Kuwait bajo la ocupación iraquí, en Nigeria y en Rumania, estas cuatro últimas hoy terminadas.

Debe también incluirse entre los mecanismos extra-convencionales de ámbito geográfico los mandatos encargados a representantes especiales de la Comisión de Derechos Humanos, tales como los mandatos sobre la situación de los derechos humanos en Ruanda; en El Salvador, después encomendado a un Experto Independiente y hoy terminado; sobre la situación de los derechos humanos en Bolivia, hoy también finalizado; y en la República Islámica del Irán, aún vigente; así 
como los mandatos encomendados a representantes especiales del Secretario General, tales como los mandatos sobre la situación de los derechos humanos en Camboya, en Polonia y en la Isla de Bougainville, de Papua Nueva Guinea, estos dos últimos terminados.

La diferencia entre los mandatos encomendados a relatores especiales y a representantes especiales, sea de la Comisión de Derechos Humanos o del Secretario General, es que mientras los primeros presentan un carácter predominantemente técnico y de investigación, los segundos presentan un matiz más político y diplomático y orientado al asesoramiento. Si bien cada mandato es en sí mismo diferente, en general los relatores especiales deben estudiar la situación de los derechos humanos en el país correspondiente y presentar un informe, con sus conclusiones y recomendaciones, a la Comisión de Derechos Humanos y, eventualmente, a la Asamblea General. Se trata en lo posible de investigar el grado de respeto de todos los derechos humanos, aunque se suele hacer hincapié en algunos de éstos, dependiendo de la situación de cada país. Así, el Relator Especial se concentrará en el análisis del respeto al derecho a la vida en un país donde el goce de este derecho esté amenazado. Otros países pueden respetar plenamente este derecho y sin embargo tener graves problemas de libertad de expresión: el Relator Especial sobre el país dará debida atención a la situación de protección de este derecho.

Por último, están los mandatos encomendados a expertos independientes, tales como los mandatos sobre la situación de los derechos humanos en Haití y en Somalia. A diferencia de los relatores y representantes Especiales, los Expertos Independientes ponen el acento en formular recomendaciones de carácter técnico orientadas a mejorar la situación de los derechos humanos en un país determinado. Así, los informes presentados por los expertos independientes sobre El Salvador, doctor Pedro Nikken, y Guatemala, doctora Mónica Pinto, constituyeron verdaderos planes de acción en derechos humanos puestos a disposición de los gobiernos respectivos.

No existen reglas precisas para que la Comisión de Derechos Humanos decida establecer un procedimiento sobre un país determinado y encomendárselo sea a un Relator Especial, a un Representante Especial o a un Experto Independiente. Se trata de países en los cuales la vigencia de los derechos humanos es motivo de particular preocupación para la comunidad internacional. En casos de situaciones persis- 
tentes de violaciones a los derechos humanos o de cuadros de violaciones graves y sistemáticas de estos derechos, la Comisión suele optar por el nombramiento de un Relator Especial, a quien le pide que investigue la situación y que le presente un informe en su próxima sesión. En casos en que los gobiernos muestren una actitud de cooperación con la Comisión y de voluntad de mejorar la situación de derechos humanos en su país, suele optarse por el nombramiento de un Representante Especial, quien tendrá un rol más diplomático. En caso de una real voluntad de mejorar la situación, la Comisión suele nombrar un Experto Independiente para que colabore con el país en el diseño de un programa de derechos humanos. La decisión, sin embargo, es en última instancia política y depende de la percepción de los miembros de la mayoría de la Comisión en un determinado momento.

Al lado de los mecanismos extra-convencionales de ámbito geográfico, las Naciones Unidas también han establecido mecanismos de carácter temático que estudian la situación de protección o de goce de un determinado derecho en todos los países del mundo. El primero de estos mecanismos fue establecido en 1980 por la Comisión de Derechos Humanos. Se trata del Grupo de Trabajo sobre Desapariciones Forzadas o Involuntarias. El Grupo de Trabajo está integrado por cinco expertos independientes, cada uno representando una región geográfica. Uno de los miembros de dicho Grupo de Trabajo es, desde 1988, el jurista peruano y profesor ordinario de la Pontificia Universidad Católica, doctor Diego García-Sayán. Posteriormente, la Comisión de Derechos Humanos estableció la Relatoría Especial sobre Ejecuciones Extrajudiciales, Sumarias o Arbitrarias, creada en 1982; la Relatoría Especial sobre la cuestión de la tortura, establecida en 1985; el Grupo de Trabajo sobre la cuestión de la detención arbitraria, constituido en 1991; la Relatoría Especial sobre la promoción y protección del derecho a la libertad de opinión y expresión, establecida en 1993 y la Relatoría Especial sobre la independencia e imparcialidad del poder judicial, los jurados y asesores y la independencia de los abogados, creada en 1994. Estos mecanismos han desarrollado un instrumento de particular eficacia y utilidad en la protección de los derechos humanos en todos los países del mundo: el procedimiento de acción urgente.

Debe también mencionarse, entre los mecanismos extra-convencionales de carácter temático, la Relatoría Especial sobre la elimina- 
ción de la violencia contra la mujer; la Relatoría Especial sobre la venta de niños, la prostitución infantil y la utilización de niños en la pornografía; el Representante Especial del Secretario General encargado de la cuestión de las repercusiones de los conflictos armados en los niños; la Relatoría Especial sobre la intolerancia religiosa; la Relatoría Especial sobre formas contemporáneas de racismo, discriminación racial, xenofobia y formas conexas de intolerancia; el mandato del Representante Especial del Secretario General sobre los desplazados internos; la Relatoría Especial sobre la cuestión de los efectos nocivos sobre el disfrute de los derechos humanos del traslado y vertimiento ilícitos de productos y desechos tóxicos y peligrosos; y la Relatoría Especial sobre la cuestión de la utilización de mercenarios como medio de violar los derechos humanos y de obstaculizar el ejercicio del derecho a la libre determinación de los pueblos. Cabe mencionar que esta última Relatoría Especial ha estado también a cargo, desde su creación en 1988, de otro destacado jurista y politólogo peruano y profesor principal de la Pontificia Universidad Católica, el doctor Enrique Bernales Ballesteros.

Existen, por último, los mecanismos establecidos para examinar la situación de los derechos económicos, sociales y culturales en todas partes del mundo. Se han establecido en esta área la Relatoría Especial sobre el derecho a la educación; y los mandatos encomendados a expertos independientes sobre el derecho al desarrollo, sobre los derechos humanos y la extrema pobreza, y sobre los efectos de las políticas de ajuste estructural en el goce efectivo de los derechos humanos.

\section{El procedimiento de acción urgente}

Algunos de los mecanismos extra-convencionales de carácter temático han desarrollado un instrumento particularmente efectivo conocido como el procedimiento de acción urgente. El mecanismo fue diseñado por el Grupo de Trabajo sobre Desapariciones Forzadas o Involuntarias de la Comisión de Derechos Humanos y fue luego incorporado a sus métodos de trabajo y aprobado por la Comisión. Hoy lo utilizan también profusamente los relatores especiales sobre Ejecuciones Extrajudiciales, Sumarias o Arbitrarias; el Relator Especial sobre la tortura; el Relator Especial sobre la independencia e imparcialidad del poder judicial, los jurados y asesores y la independencia de los 
abogados; el Relator Especial sobre el derecho a la libertad de opinión y de expresión; la Relatora sobre violencia contra la mujer y el Grupo de Trabajo sobre Detención Arbitraria.

El procedimiento consiste básicamente en lo siguiente: tan pronto como el familiar de una víctima de una violación grave de los derechos humanos tiene conocimiento de ésta, sea directamente o a través de una organización no gubernamental, puede ponerla en conocimiento de uno de los mecanismos mencionados en el párrafo anterior a través de la Oficina del Alto Comisionado de las Naciones Unidas para los Derechos Humanos en Ginebra, sea mediante mensaje electrónico (e-mail), facsímil, cable o télex. El mecanismo correspondiente analizará si la comunicación menciona al menos los siguientes cinco elementos: a) nombre completo de la víctima y otros datos que contribuyan a su identificación (fecha y lugar de nacimiento, nacionalidad, profesión, documentos de identidad, etc.); b) fecha en que ocurrió la violación de los derechos humanos; c) lugar en el cual ocurrieron los hechos; d) las partes que se presume cometieron la violación de los derechos humanos; y e) las medidas adoptadas internamente para subsanar la situación.

Nótese que la efectividad del procedimiento de acción urgente deriva en gran parte en que no se requiere, como en otras instancias internacionales, el agotamiento previo de los recursos internos. Esto confiere al mecanismo una gran rapidez y efectividad.

Tan pronto se recibe la denuncia respectiva el mecanismo correspondiente revisa si la comunicación contiene los elementos mínimos de información exigidos. De ser así, el Presidente del Grupo de Trabajo, o el Relator Especial que corresponda, envía una carta por facsímil al Ministro de Relaciones Exteriores del país donde se produjeron los hechos, pidiéndole que las autoridades de su Estado investiguen lo sucedido y que le comunique, tan pronto como le sea posible, cualquier información pertinente sobre los resultados de esas investigaciones. Cualquier respuesta que el Gobierno proporcione, o el hecho de que el Gobierno no proporcione ninguna respuesta, serán incluidas en el informe que el Grupo de Trabajo somete a la Comisión de Derechos Humanos y que suele tener una amplia divulgación pública, hoy aumentada por su difusión mundial por Internet.

Considérese, por ejemplo, que en muchos países, elementos subalternos de las fuerzas de orden o de seguridad o miembros de grupos 
paramilitares que actúan con la aquiescencia de estos, continúan deteniendo personas sin orden judicial y negando luego su detención. Se trata muchas veces de víctimas anónimas, pobres, analfabetas o desempleadas, que quedan así indefensos ante sus captores. Su situación puede cambiar radicalmente si el Ministro de Relaciones Exteriores de su país, alertado por las Naciones Unidas, pide informes y acciones concretas a los ministros de Defensa, Seguridad o Interior sobre el caso comunicado y si éstos las demandan, a su vez, a sus subordinados. El detenido podrá así, si procede, ser liberado o, al menos, su detención será reconocida y la posibilidad de que sea víctima de torturas o malos tratos o de una desaparición forzada habrá sido considerablemente reducida.

Durante 1998, el Grupo de Trabajo sobre Desapariciones Forzadas o Involuntarias de la Comisión de Derechos Humanos envió llamamientos urgentes a veintitrés Estados, con respecto a 209 casos de desaparición forzada o involuntaria que ocurrieron dentro de los tres meses anteriores al recibo de la denuncia por el Grupo de Trabajo (1/ E/CN.4/1999/62, párr. 3). Durante el mismo año, el Grupo de Trabajo sobre la Detención Arbitraria envió 83 llamamientos urgentes a treintisiete Estados (y a la Autoridad Nacional Palestina) relativos a la detención presuntamente arbitraria de 763 personas (2/E/CN.4/1999/ 63, párr. 15). Este Grupo de Trabajo se limita a señalar a los gobiernos respectivos los casos específicos que se le han denunciado, sin prejuzgar la decisión final que adoptará acerca de si la detención es o no arbitraria. Recurre al procedimiento de acción urgente, principalmente cuando se trata de la detención presuntamente arbitraria de personas en estado de salud crítico, o cuando las autoridades administrativas hacen caso omiso de órdenes judiciales de puesta en libertad. Ambos grupos de trabajo recuerdan a los gobiernos sus obligaciones de garantizar el respeto de los derechos a la vida y a la integridad de las personas detenidas.

El Relator Especial sobre la cuestión de la tortura recurre también al procedimiento de acción urgente cuando la denunciante ha expresado temores de que la persona detenida pueda ser sometida a torturas $\mathrm{u}$ otros tratos crueles, inhumanos o degradantes. Exige sí que la denunciante sea una fuente creíble y fidedigna prima facie (3/E/CN.4/ 1999/61, párr. 11). Durante 1998, el Relator Especial transmitió 122 llamamientos urgentes a veintiún Estados que hacían referencia a 380 
personas y veinte grupos de alrededor de 1,500 personas en total, incluyendo un grupo de 190 mujeres. También la Relatoría Especial sobre ejecuciones extrajudiciales, sumarias o arbitrarias hace un uso extenso de este recurso: en el año referido, 1998, transmitió 63 llamamientos urgentes a los gobiernos de treinta países y un llamamiento urgente al presidente del Consejo Talibán. Los llamamientos urgentes transmitidos por la Relatora Especial se referían a 158 personas (4/ E/ CN.4/1999/39, párr. 12). En treintiseis casos, se trató de personas que habían sido condenadas a muerte luego de procesos judiciales irregulares, en los que no se había observado las normas del debido proceso u otros principios internacionales. En veinte casos, se trató de personas que habían sido amenazadas de muerte por parte de funcionarios del Estado o de miembros de grupos paramilitares que cooperaban con las fuerzas de seguridad o eran toleradas por éstas. En otros dos casos se trató de personas privadas de libertad cuyas vidas corrían peligro por las palizas y los malos tratos que recibían durante su detención.

El Relator sobre la independencia de magistrados y abogados transmitió también once llamamientos urgentes a ocho Estados (5/ E/CN.4/ 1999/60, párr. 19) y el Relator Especial sobre la protección y la promoción del derecho a la libertad de opinión y de expresión ha adoptado también un procedimiento de acción urgente para los casos en que hayan vidas en peligro y otras situaciones particularmente graves ( 6/ E/CN.4/1999/64, Anexo).

El procedimiento de acción urgente fue concebido por el Grupo de Trabajo sobre Desapariciones Forzadas o Involuntarias atendiendo a razones fundamentalmente humanitarias y a la necesidad de proteger a las víctimas. El procedimiento se basa en el mandato del Grupo de Trabajo, establecido en la resolución 20 (XXXVI) de la Comisión de Derechos Humanos, y se orienta hacia el logro de su objetivo principal: ayudar a las familias a determinar la suerte y el paradero de los parientes que, por haber desaparecido, se encuentran fuera del amparo de la ley. El Grupo de Trabajo se esfuerza por establecer un cauce de comunicación entre las familias y los gobiernos de que se trate, con el fin de que se aclare el paradero de la persona desaparecida (7/ Alto comisionado de las Naciones Unidas para los derechos humanos. Desapariciones Forzadas o Involuntarias, Oficina de las Naciones Unidas en Ginebra, Ginebra, Diciembre de 1997, p. 7). Algunos ju- 
ristas perciben en él, sin embargo, posibilidades de evolución hasta convertirse en una suerte de recurso de amparo internacional (8/ Véase por ejemplo Carlos Villán Durán, The Practice of the Human Rights Commission in the Development of Extra-conventional Mechanisms for the International Protection of Human Rights. En: Studie-en Informatiecentrum Mensenrechten, Revista del Netherlands Institute of Human Rights, Special Number 13, The Hague, 1991, p. 26).

Según Villán Durán, "the urgent action system is eminently protective and resembles a kind of international habeas corpus in which the communication is received and handled with promptness and flexibility, without heeding admissibility requirements such as the exhaustion of internal remedies or the consent of the State» ( $9 /$ op. cit). Villán Durán llega a vislumbrar que esta suerte de recurso de amparo internacional se presentaría ante y sería sustanciado por la Alta Comisionada de las Naciones Unidas para los Derechos Humanos, quien se constituiría así en la base de un sistema permanente e institucionalizado de tutela inmediata de los derechos humanos. Esta evolución del procedimiento de acción urgente requeriría proveerle de las salvaguardias mínimas necesarias a todo recurso de garantía, lo que podría atentar contra su actual flexibilidad y hacerlo más rígido.

\section{Las visitas en misión oficial}

Otro de los instrumentos que ha alcanzado particular desarrollo, en los últimos años, son las visitas en misión oficial que los grupos de trabajo y los relatores y representantes especiales de la Comisión de Derechos Humanos realizan a los diferentes países. El Grupo de Trabajo sobre Desapariciones Forzadas o Involuntarias ha visitado el Perú en dos oportunidades, Colombia, Guatemala y Filipinas. En 1998 visitó Turquía y Yemén y en 1999 realizó una visita de seguimiento a Sri Lanka, para examinar el cumplimiento de las recomendaciones que el Grupo de Trabajo había realizado a dicho país en ocasión de dos visitas anteriores. El Grupo de Trabajo sobre la Detención Arbitraria visitó Bhután y Viet Nam en 1994; Nepal en 1996; efectuó una visita de seguimiento a Bhután en 1996; visitó China en 1997 y el Perú; Rumania y el Reino Unido de Gran Bretaña e Irlanda del Norte en 1998. Visitó también Indonesia en 1999. 
Por su parte, la Relatora Especial sobre Ejecuciones Extrajudiciales, Sumarias o Arbitrarias ha visitado recientemente Albania, México y la ex-República Yugoslava de Macedonia. El Relator Especial anterior visitó el Perú en 1993; Burundi, la Isla de Bougainville en Papúa Nueva Guinea e Indonesia y el Timor Oriental en 1995; Sri Lanka y los Estados Unidos de América en 1997. El Relator sobre la cuestión de la tortura ha visitado la República Árabe de Egipto en 1993; la Federación de Rusia en 1994; Pakistán y Venezuela en 1996; México en 1997; Turquía en 1998 y Rumania y el Timor Oriental en 1999; y el Relator sobre la independencia de magistrados y abogados visitó Bélgica, Colombia, el Perú y el Reino Unido en 1997.

Las visitas en misión oficial a países permiten a los grupos de trabajo y a los relatores especiales ir más allá de la simple consideración de casos y situaciones individuales y concentrarse en el conocimiento de la vigencia y el grado de protección de un determinado derecho en un país concreto. Esto permite conocer y analizar las causas, consecuencias y efectos del grado de protección efectiva de un determinado derecho y el contexto general del país. Las visitas en misión suelen dividirse en una parte oficial, que incluye entrevistas y reuniones de trabajo con autoridades gubernamentales y representantes de los distintos poderes del Estado, y una parte extraoficial que incluye las reuniones con los representantes de organizaciones no gubernamentales; entrevistas con testigos de violaciones de derechos humanos, y reuniones con familiares de las víctimas. El Relator o Representante Especial tendrá así una opinión cabal de lo que sucede realmente en el país y no dependerá en sus informes exclusivamente de fuentes escritas o de documentos que les sean proporcionados. Los gobiernos, por su parte, tienen la ocasión de hacer una presentación de la situación real en el país y de facilitar el contacto de los representantes internacionales con toda clase de autoridades y funcionarios políticos, judiciales, administrativos, penitenciarios, civiles o militares.

Esta misma oportunidad se presenta para los defensores de derechos humanos, miembros de organizaciones no gubernamentales de carácter local, de partidos políticos y familiares de las víctimas. Los relatores especiales y miembros de grupos de trabajo suelen viajar a provincias, y entre éstas suelen escoger las más afectadas y relevantes a su mandato. Si la visita ha sido concienzudamente preparada, tanto por el representante internacional como por el gobierno respectivo y 
los representantes de las organizaciones de la sociedad civil, el informe final contendrá conclusiones acertadas y recomendaciones que serán útiles para el país, desde que han sido formuladas por los principales expertos internacionales en la materia.

Los grupos de trabajo, relatores y representantes especiales y expertos independientes de la Comisión de Derechos Humanos están permanentemente en disposición de recibir invitaciones de gobiernos para visitar sus países. En ocasiones, cuando el cabal desempeño de su mandato así lo exige, toman la iniciativa de demandar a un gobierno que les curse la invitación correspondiente para realizar una visita a su país en misión oficial. En este último caso, no se trata solamente de países que presentan una situación particularmente grave respecto a la vigencia de un determinado derecho, sino también de países que, en el otro extremo, han tenido una experiencia positiva en la superación de una situación o en la promoción de un derecho y cuya experiencia pueda resultar útil a los demás.

En ciertos casos en los cuales se formularon recomendaciones a un país luego de una visita, y transcurrido un cierto lapso desde la misma, conviene realizar misiones de seguimiento a fin de conocer el grado de cumplimiento de las recomendaciones formuladas en su oportunidad o los obstáculos encontrados para su implementación. Es lo que el Grupo de Trabajo sobre Desapariciones Forzadas o Involuntarias hizo en octubre de 1999 con respecto a Sri Lanka.

\section{Defendiendo a los defensores}

Uno de los hechos más preocupantes observados durante los últimos años a nivel internacional es que conocidos defensores de los derechos humanos, miembros de organizaciones no gubernamentales, personas que han cooperado o cooperan con los grupos de trabajo, relatores y representantes especiales y expertos independientes proporcionándoles información y personas que han prestado testimonio ante ellos, son percibidos como elementos hostiles por integrantes de algunos gobiernos y se convierten a su vez en víctimas de actos de hostigamiento, intimidación y represalias, e incluso, en algunos casos particularmente graves, de violaciones a los derechos humanos. Cabe reparar en el hecho que aun cuando no sean percibidos como elementos hostiles, estas 
personas tienen acceso a documentación que puede resultar comprometedora y contactos con personas que pueden estar siendo perseguidas por la justicia o viviendo en la clandestinidad. En general, el simple desempeño de su trabajo suele colocarlos en una posición incómoda frente a las autoridades, particularmente en países sometidos a regímenes autoritarios.

El Grupo de Trabajo sobre Desapariciones Forzadas o Involuntarias ha incorporado a sus métodos de trabajo el procedimiento de intervención rápida aplicable a los casos de persecución, intimidación o represalias contra los familiares de las personas desaparecidas que se han puesto en contacto con el Grupo, contra sus asesores jurídicos, los testigos de las desapariciones y los miembros de organizaciones no gubernamentales. Al recibir una queja sobre presuntos actos de intimidación, persecución o represalia, el Grupo de Trabajo transmite su preocupación al Ministro de Relaciones Exteriores correspondiente por la vía más directa y rápida, generalmente por facsímil, urgiendo al gobierno a que adopte todas las medidas de protección necesarias y a que le informe de las medidas adoptadas. Otros relatores especiales también han empezado a transmitir llamamientos urgentes en favor de personas que realizan actividades pacíficas en defensa de los derechos humanos.

La Comisión de Derechos Humanos ha venido pidiendo durante los últimos años a todos los representantes de los órganos de derechos humanos de las Naciones Unidas, que sigan adoptando medidas urgentes, de conformidad con sus mandatos, para tratar de impedir que se obstaculice el acceso a los procedimientos de derechos humanos de las Naciones Unidas; que se produzcan actos de intimidación y represalias contra las personas señaladas; y que sigan incluyendo en sus informes una referencia a las acusaciones de intimidación o represalias y una relación de las medidas que hayan adoptado a ese respecto. También ha pedido al Secretario General que le presente una compilación y un análisis de toda la información que recabe sobre presuntas represalias, lo que el Secretario General ha venido haciendo (10/ Véase las resoluciones 1990/76, 1991/70; 1992/59; 1993/64; 1994/70; 1995/ 75; 1996/70 y 1997/56 de la Comisión de Derechos Humanos). 


\section{Conclusión: Identificando las causas de las violaciones a los dere- chos humanos}

Los mecanismos extra-convencionales fueron establecidos para estudiar, a nivel global, el estado de promoción, protección y vigencia de un aspecto de un determinado derecho, tal como el derecho a la vida, a la integridad, a la libertad, a la seguridad o a la propiedad, o una determinada violación a los derechos humanos. Surgieron así los grupos de trabajo sobre las desapariciones forzadas o involuntarias y sobre la detención arbitraria; las relatorías especiales sobre las ejecuciones extrajudiciales, sumarias o arbitrarias, sobre la cuestión de la tortura, sobre la libertad de opinión y expresión o sobre la independencia del Poder Judicial, de los magistrados y abogados, entre otras. En un segundo momento estos mecanismos comenzaron a actuar sobre casos individuales y crearon procedimientos bastante efectivos y rápidos, tales como el procedimiento de acción urgente y el procedimiento de intervención rápida, que se han examinado en este artículo.

Esta acción ha sido bastante exitosa en lo que se refiere a casos individuales. Sin embargo, resulta necesario ir más allá, hasta determinar qué factores se han dado para que surja una situación de violación persistente, masiva o sistemática de un determinado derecho en un país o región determinada. En otras palabras, determinar las causas de estas situaciones de no vigencia de los derechos humanos y los factores que actúan para que estas situaciones persistan y no sean superadas.

Los grupos de trabajo, los relatores y representantes especiales y expertos independientes están en una magnífica posición para poder hacerlo. Estudian la realidad de la vigencia del derecho que les preocupa y que les ha tocado examinar, en todos los países y territorios del mundo. Algunos tienen ya varios años en el cargo y han acumulado una rica experiencia que les permite observar la evolución de los fenómenos que estudian, a través del tiempo. Ellos mismos provienen de regiones muy diferentes y representan una gran variedad de sistemas jurídicos, desde el tradicional derecho romano hasta el common law anglo-sajón, pasando por sistemas tradicionales, islámicos, germánicos o socialistas. Sus informes han llegado a la siguiente conclusión general y fundamental: La principal causa de la persistencia de situaciones de violaciones graves o sistemáticas de los derechos humanos es la impunidad que se otorga a los responsables de dichas violaciones. El 
hecho de que los culpables de violaciones graves a los derechos humanos sean eximidos de la obligación de rendir cuenta de sus actos ante la sociedad y no sean sancionados por los mismos es el principal obstáculo a una superación de la situación y a una evolución hacia un estado en el que se respeten los derechos humanos.

El anterior Relator Especial sobre las ejecuciones extrajudiciales, sumarias o arbitrarias señaló en uno de sus informes: «Incluso si por circunstancias excepcionales un gobierno decide que los responsables de violaciones a los derechos humanos podrán acogerse a medidas que les eximan de castigo o que limiten la severidad de éste, subsiste la obligación del gobierno de juzgarles y considerarles responsables ante la ley" (11/ A/51/457, párr. 120). El Grupo de Trabajo sobre Desapariciones Forzadas o Involuntarias anotó por su parte en su informe correspondiente al año 1990: "La impunidad es quizás el más importante factor singular que contribuye al mantenimiento de las desapariciones forzadas" (12/ E/CN.4/1991/20, párr. 406).

Otros factores señalados son los siguientes: a) la falta de democracia o elevados niveles de déficit democrático; b) la falta de respeto al imperio del derecho; c) la falta de independencia del Poder Judicial, de los jueces, miembros de jurados, abogados, fiscales, personal judicial y auxiliares de justicia; d) la falta de garantías para el libre ejercicio de las profesiones jurídicas (13/ E/CN.4/1999/60, párr. 36); e) el abuso de los estados de emergencia o excepción; f) la falta de proporcionalidad entre las medidas adoptadas y la situación que motiva la emergencia; g) el ejercicio de poderes y facultades propios de un estado de emergencia sin que haya mediado la declaración formal de dicho estado; h) mala tipificación o descripciones demasiado vagas de las conductas incriminadas en caso de delitos contra la seguridad nacional o la seguridad del Estado; i) la existencia de jurisdicciones especiales o de excepción; j) ausencia o déficit de adecuadas garantías procesales; $\mathrm{k}$ ) ausencia o limitaciones de los recursos de hábeas corpus y amparo; 1 ) la falta de cultura de derechos humanos; $m$ ) la ausencia de tipificación o la mala definición en la legislación nacional de los delitos de desaparición forzada o involuntaria y de tortura como delitos contra la humanidad; n) el otorgamiento a las fuerzas de seguridad de amplios poderes de arresto y detención, que autorizan a sus miembros a efectuar detenciones sin exhibir mandato judicial, vestidos de civil y utilizando vehículos sin placas de matrícula; o) la posibilidad legal de 
mantener a los detenidos en situación de incomunicado durante largos períodos; p) la ausencia de registros centrales computarizados de detenidos y de registros diarios de detenciones (14/ E/CN.4/1994/26, párr. 86); q) La imposibilidad de las autoridades judiciales, fiscales o de la Oficina del Defensor del Pueblo de visitar centros, cuarteles e instalaciones militares; r) la vigencia de leyes de amnistía, de punto final, de obediencia debida y de plazos sumamente cortos de prescripción para delitos que implican violaciones a los derechos humanos; s) la falta de suficientes recursos humanos y presupuestales asignados al Poder Judicial y al Ministerio Público; t) la inexistencia de Ombudsman o Defensor del Pueblo y de instituciones nacionales de protección y promoción de los derechos humanos.

Estos son sólo algunos de los obstáculos que han sido identificados por los grupos de trabajo, relatores, representantes especiales y expertos independientes de la Comisión de Derechos Humanos de las Naciones Unidas. La tarea de quienes creen en la necesidad del imperio del derecho y de la vigencia plena de la democracia y de los derechos humanos consiste en tratar de empezar a superarlos en todo el mundo. 